\title{
Camera trapping reveals area of conservation significance for large and medium-sized mammals on the eastern Tibetan Plateau
}

\author{
Yu Xu, Bin Wang, Xiaodong Gu, Dazhao Song and Biao Yang
}

\begin{abstract}
The eastern margin of the Tibetan Plateau, a global biodiversity hotspot, is threatened by habitat degradation. Conservation actions are required in this region, but limited knowledge of large and medium-sized mammals is hampering conservation planning. Using 149 camera traps, we surveyed large and medium-sized mammals in Xionglongxi Provincial Nature Reserve and adjacent areas, on the eastern margin of the Tibetan Plateau, during September 2016-May 2017. We obtained 5,752 independent captures of 29 large and medium-sized mammal species, including 13 that are globally threatened and 22 that are nationally threatened in China. Carnivores were especially diverse, with 16 species recorded. Of particular significance was our detection of seven felid species, including the leopard Panthera pardus and the snow leopard Panthera uncia. Our record of the Chinese mountain cat Felis bieti extends the known range of this species. We documented new upper elevation limits for eight species. There was elevational overlap between the leopard and the snow leopard, suggesting potential competition between the two species. The grey wolf Canis lupus and the leopard were the dominant predators, and the woolly hare Lepus oiostolus and several species of ungulates were the most frequently photographed prey species. The study area maintains a significant community of large and medium-sized mammals, which is more diverse than in other areas on the eastern edge of the Tibetan Plateau. We recommend the establishment of a larger nature reserve of national protection status in the region of the Xionglongxi Provincial Nature Reserve, to protect the unique subalpine and alpine ecosystems in this area.
\end{abstract}

YU XU* (D orcid.org/0000-0002-9437-3267) School of Life Sciences, Guizhou Normal University, Guiyang, China

BIN WANG Key Laboratory of Southwest China Wildlife Resource Conservation (Ministry of Education), China West Normal University, Nanchong, China

XIAODONG Gu Sichuan Forestry and Grassland Bureau, Chengdu, China

Dazhao Song China Felid Conservation Alliance, Chongqing, China

BIAO YANG $\dagger$ (Corresponding author) Key Laboratory of Southwest China Wildlife Resource Conservation (Ministry of Education), China West Normal University, Nanchong 637002, China. E-mail yangb315@163.com

${ }^{*}$ Also at: School of Chemical and Environmental Engineering, Pingdingshan University, Pingdingshan, China

†Also at: Chengdu Research Base of Giant Panda Breeding, Chengdu, China

Received 14 August 2019. Revision requested 12 November 2019.

Accepted 15 April 2020. First published online 9 March 2021.
Keywords Camera trapping, carnivores, felids, Felis bieti, mammals, threatened species, Tibetan Plateau, Xionglongxi Nature Reserve

\section{Introduction}

The mountains of south-west China, including the Hengduan, Nujiang Langcang Gorge and QionglaiMinshan Mountains, are recognized as a global biodiversity hotspot (Myers et al., 2000; Mittermeier et al., 2004). The eastern margin of the Tibetan Plateau forms part of the Hengduan Mountains, and is a transitional zone between the subalpine conifer forests of the Hengduan Mountains and the alpine scrublands and meadows of the Tibetan Plateau. The region features a complex topography and a variety of vegetation types, including mixed conifer and broad-leaved forests, subalpine conifer forests, alpine scrublands, and meadows and tundra. It is believed to be rich in biodiversity, owing to species differentiation caused by the orographic uplift of the Tibetan Plateau (Zhang et al., 2002). However, human activities are threatening the biodiversity in the region. Although commercial logging and hunting have been banned following China's Natural Forest Conservation Programme in 1998, forests are still the primary source of wood for household use (e.g. for construction, and fuel for cooking and heating), and many areas in the region are intensively used for grazing and the gathering of food and traditional medicines (Brandt et al., 2012). In addition, despite the remoteness of these areas, rapid economic development and human population growth have resulted in an increasing demand for infrastructure development and a rapid expansion of extractive (e.g. hydropower and mining) and tourism industries (Brandt et al., 2012; Xinhua, 2018). These activities accelerate habitat loss and fragmentation, and place biodiversity under increasing threat throughout the region (Brandt et al., 2012; Zhao \& Lu, 2017). The conservation of the region's unique biodiversity requires dedicated efforts in research, conservation planning and implementation.

Large and medium-sized mammals, particularly carnivores such as felids, are key indicators for biodiversity conservation and management (Dickman et al., 2015; Xiao et al., 2017). Confirmed presence of large and/or mediumsized mammal species provides insights into the community composition and structure, and is an indicator of ecosystem 
health (Hedwig et al., 2017). Mammals on the eastern edge of the Tibetan Plateau have been studied since the mid 19th century, when European and American explorers, missionaries and expeditions entered the region to collect specimens (Shi \& Zhao, 1982). In the mid 2oth century, Chinese researchers began to investigate mammals in the area (Shi \& Zhao, 1982). In particular, after the founding of the People's Republic of China in 1949, surveys were conducted in the region (Wu et al., 1989; Peng et al., 2006; Shen, 2008), including two national surveys on terrestrial wildlife (State Forestry Administration, 2009; SCOL, 2013). Nevertheless, much of the region has yet to be surveyed and knowledge of the diversity of large and medium-sized mammals remains limited (Sichuan Observer, 2017; Chinanews, 2018; Hu et al., 2019; People.cn, 2019). Photographic records of mammals are particularly scarce (Xiao et al., 2017). Other ecoregions in the hotspot, such as Qionglai-Minshan conifer forests, have been studied more thoroughly and are known to harbour flagship species for conservation, including the giant panda Ailuropoda melanoleuca and the golden monkey Cercopithecus kandti.

Here, we conducted camera-trap surveys of large and medium-sized mammals on the eastern edge of the Tibetan Plateau. Camera traps have become a valuable tool for wildlife surveys (Ancrenaz et al., 2012; Burton et al., 2015) and are effective in monitoring rare or elusive animals such as felids (Carbone et al., 2001). Camera trapping can form the basis of effective long-term monitoring of wildlife and can help document population changes ( $\mathrm{Li}$ et al., 2014; Burton et al., 2015). Our objectives were to compile a species inventory and provide an initial assessment of the relative abundance of species, to ascertain the potential importance of this area for conservation.

\section{Study area}

We conducted the study in Xionglongxi Provincial Nature Reserve and adjacent areas, in Xinlong County, Garzê Tibetan Autonomous Prefecture, Sichuan Province, China. The area is located c. $600 \mathrm{~km}$ from Chengdu, the capital of Sichuan Province (Fig. 1a) and covers $1,872 \mathrm{~km}^{2}\left(582 \mathrm{~km}^{2}\right.$ in the Reserve and $1,290 \mathrm{~km}^{2}$ in adjacent areas). It is characterized by complex topography around the mid Yalong River valleys. A monsoon-influenced humid continental climate and subarctic climate predominate, with cold and dry winters, and warm summers with frequent rain (Zhu \& Xiang, 2015). The vegetation comprises meadows or tundra $(41.7 \%)$, conifer forests $(27.8 \%)$, scrubs $(28.3 \%)$ and broadleaf forests (2.3\%; National Forestry and Grassland Data Center, Sichuan Subcenter, 2020). Potentially harmful human activities include timber extraction for household use (e.g. for construction, and fuel for cooking and heating), illegal hunting, livestock grazing, and the gathering of food and traditional medicines. In particular, with the implementation of the Natural Forest Conservation Programme, grazing may have become the most prevalent human disturbance in the area, as a result of incentives from local governments to develop alternative livelihoods to reduce timber harvesting.

\section{Methods}

\section{Camera trapping}

We conducted camera-trap surveys during September 2016May 2017. As the purpose of the study was to provide an initial species inventory, we prioritized capturing a high diversity of species over enabling statistical inference on populations (e.g. occupancy modelling). We installed camera traps (Ltl Acorn 6210/6310 series, Zhuhai Ltl Acorn Electronics Co., Zhuhai, China, and Loreda L510 series, Shenzhen Loreda Electronics Co., Shenzhen, China) in areas where high levels of wildlife activity had been reported by staff of the Reserve and the Forestry Bureau. In total, we installed 149 camera traps, placed on animal trails and ridge tops or near waterholes, at 3,100-4,860 m altitude. Of the 149 camera traps, $10.2 \%$ were placed in broadleaf forests, $44.2 \%$ in conifer forests, $21.8 \%$ in scrubs and $23.8 \%$ in meadows or tundra (Fig. 1b). The mean distance between cameras was $2.37 \pm \mathrm{SD} 1.33 \mathrm{~km}$. The cameras used infrared lighting and operated continuously, with motion sensors set to trigger immediately and to take a sequence of three photographs when movement was detected. The camera traps did not use white flash that may have a greater risk of startling animals. We collected the photographic data every 3-4 months.

\section{Data analysis}

We defined large and medium-sized mammals as any mammal species with a mean body mass $>0.5 \mathrm{~kg}$ (Bruce et al., 2018). We identified species based on Wang \& $\mathrm{Hu}$ (1999), Peng \& Zhong (2005), Smith \& Xie (2009) and Jiang et al. $(2015,2017)$. We assessed species' conservation significance on a global and national level according to the threat categories assigned in the IUCN Red List (IUCN, 2019) and the Red List of China's Vertebrates (Jiang et al., 2016), respectively.

We calculated survey effort as the total number of camera-trap days. We considered a single capture event as any sequence for a given species taken $>30$ minutes after the previous sequence of that species at the same location (O'Brien et al., 2003; Moo et al., 2017). We calculated the total number of independent capture events of individual species (e.g. Moo et al., 2017) and the per cent of camera-trap stations at which each species was detected (e.g. Rovero et al., 2014; Moo et al., 2017). We did not calculate relative 

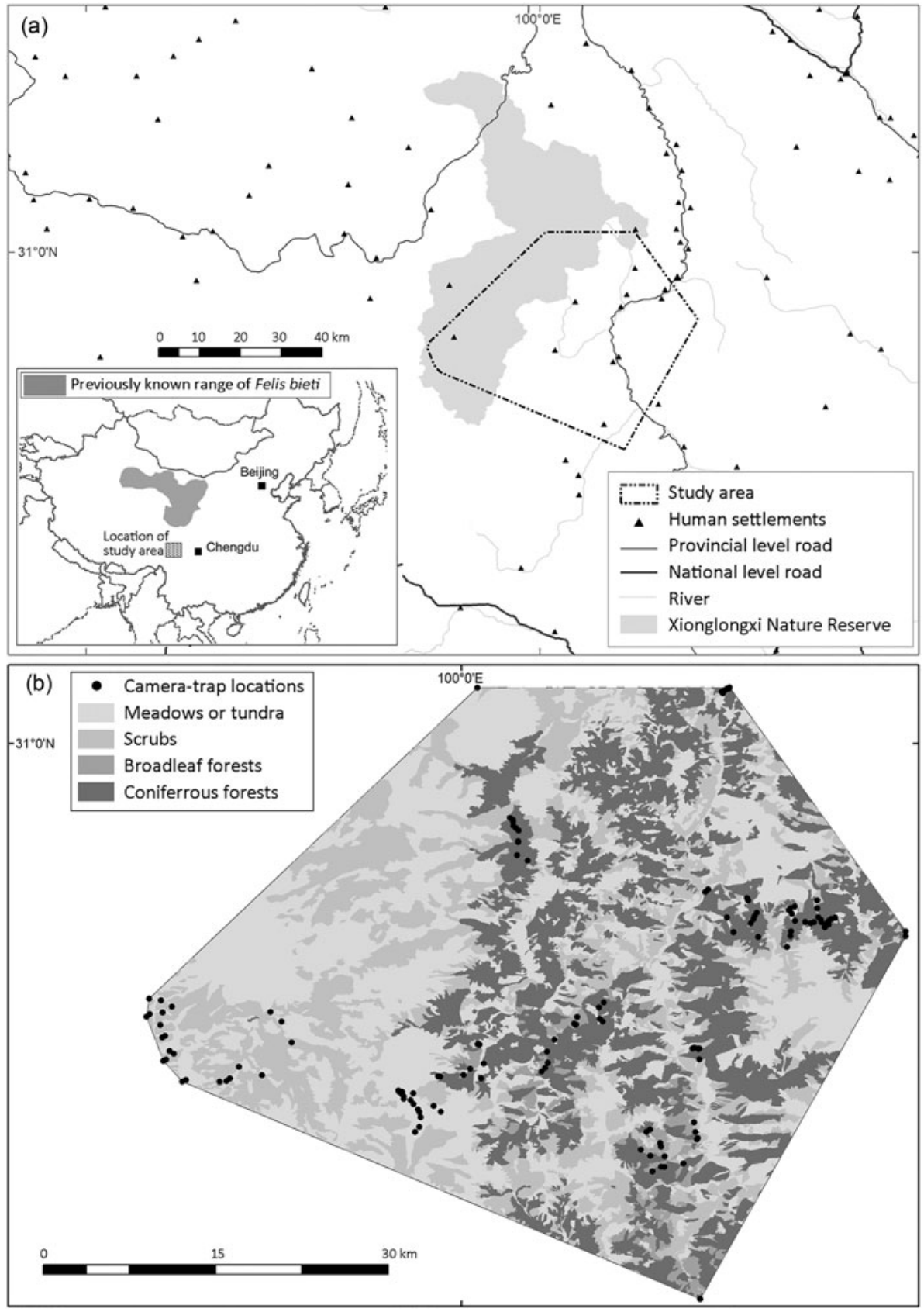

FIG. 1 (a) The study area in Xionglongxi Provincial Nature Reserve and adjacent areas, Xinlong County, Sichuan Province, China. The inset map illustrates the previously known range of the Chinese mountain cat Felis bieti. (b) Locations of camera traps. The locations of two camera traps are not shown because of errors in the recording of longitude and latitude data. abundance indices suggested by Carbone et al. (2001) and O'Brien et al. (2003), because comparisons using this technique are not statistically valid given significant variation in detectability between species and areas (Sollmann et al., 2013; Burton et al., 2015; Anile \& Devillard, 2016; Li et al., 2016).

\section{Results}

Of the 149 camera-trap locations, 27 failed to generate usable data because of camera malfunction or loss. Over a total of 15,455 camera-trap days, we obtained 5,752 independent captures and identified 29 species of large and mediumsized mammals belonging to five orders and 12 families. Of the 29 species detected, two are categorized as Endangered on the IUCN Red List, six as Vulnerable, and five as Near Threatened; four are categorized as Critically Endangered on the Red List of China's Vertebrates, five as Endangered, six as Vulnerable, and seven as Near Threatened (Table 1).

Thirteen species occurred in all four habitats (broadleaf forest, conifer forest, scrubs, and meadow or tundra) over different elevations, and 16 occurred only in some habitats (Table 1). Of the latter, six species (the snow leopard Panthera uncia, Pallas's cat Otocolobus manul, the blue 
TABLE 1 The large and medium-sized mammals camera-trapped in Xionglongxi Provincial Nature Reserve and adjacent areas, Xinlong County, Sichuan Province (Fig. 1), China, during September 2016-May 2017, with their status on the IUCN Red List (IUCN, 2019) and the Red List of China's Vertebrates (Jiang et al., 2016), previously known elevational limits, elevational range observed in the study area, per cent of camera-trap stations at which each species was detected, and the total number of independent capture events of each species in a total of 15,455 camera-trap days.

\begin{tabular}{|c|c|c|c|c|c|c|c|}
\hline Species (by order) & $\begin{array}{l}\text { IUCN } \\
\text { Red List } \\
\text { status }\end{array}$ & $\begin{array}{l}\text { China's } \\
\text { Vertebrates } \\
\text { Red List status }\end{array}$ & $\begin{array}{l}\text { Previously known } \\
\text { elevational limits } \\
(\mathrm{m})^{1}\end{array}$ & $\begin{array}{l}\text { Elevational } \\
\text { range } \\
\text { observed }(\mathrm{m})\end{array}$ & $\begin{array}{l}\text { Habitat } \\
\text { types }^{2}\end{array}$ & $\begin{array}{l}\% \text { of traps that } \\
\text { recorded the } \\
\text { species }\end{array}$ & $\begin{array}{l}\text { Total no. of } \\
\text { independent } \\
\text { capture events }\end{array}$ \\
\hline \multicolumn{8}{|l|}{ Primates } \\
\hline Rhesus monkey Macaca mulatta & LC & LC & $0-4,000$ & $3,252-4,375$ & $\mathrm{~B}, \mathrm{C}, \mathrm{S}, \mathrm{MT}$ & 0.41 & 184 \\
\hline \multicolumn{8}{|l|}{ Carnivora } \\
\hline \multicolumn{8}{|l|}{ Canidae } \\
\hline Grey wolf Canis lupus & LC & NT & $0-3,000$ & $3,252-4,843$ & B, C, S, MT & 0.58 & 646 \\
\hline Red fox Vulpes vulpes & LC & NT & $0-4,500$ & $3,105-4,865$ & $\mathrm{~B}, \mathrm{C}, \mathrm{S}, \mathrm{MT}$ & 0.61 & 538 \\
\hline \multicolumn{8}{|l|}{ Ursidae } \\
\hline Brown bear Ursus arctos & LC & VU & $0-5,000$ & $3,615-4,135$ & $\mathrm{C}, \mathrm{S}$ & 0.12 & 22 \\
\hline Asiatic black bear Ursus thibetanus & VU & VU & $0-4,300$ & $3,521-4,208$ & B, C, S & 0.07 & 16 \\
\hline \multicolumn{8}{|l|}{ Mustelidae } \\
\hline Siberian weasel Mustela sibirica & LC & LC & $0-4,875$ & $3,450-4,375$ & $\mathrm{~B}, \mathrm{C}, \mathrm{S}, \mathrm{MT}$ & 0.18 & 51 \\
\hline Altai weasel Mustela altaica & NT & NT & $80-4,900$ & 4,068 & $\mathrm{C}$ & 0.01 & 2 \\
\hline Northern hog badger Arctonyx albogularis & $\mathrm{LC}$ & NT & $0-4,300$ & $3,686-4,824$ & $\mathrm{~B}, \mathrm{C}, \mathrm{MT}$ & 0.06 & 12 \\
\hline Asian badger Meles leucurus & LC & NT & $0-3,205$ & 3,904 & $\mathrm{C}$ & 0.01 & 1 \\
\hline Yellow-throated marten Martes flavigula & LC & NT & $0-4,510$ & $3,105-4,310$ & $\mathrm{~B}, \mathrm{C}, \mathrm{S}, \mathrm{MT}$ & 0.34 & 113 \\
\hline \multicolumn{8}{|l|}{ Felidae } \\
\hline Leopard Panthera pardus & VU & $\mathrm{EN}$ & $0-5,200$ & $3,120-4,360$ & $\mathrm{~B}, \mathrm{C}, \mathrm{S}, \mathrm{MT}$ & 0.44 & 130 \\
\hline Snow leopard Panthera uncia & VU & $\mathrm{EN}$ & $500-5,800$ & $4,765-4,865$ & S, MT & 0.06 & 27 \\
\hline Eurasian lynx Lynx lynx & LC & EN & $0-5,500$ & $3,840-4,813$ & $\mathrm{C}, \mathrm{S}, \mathrm{MT}$ & 0.09 & 14 \\
\hline Asiatic golden cat Catopuma temminckii & NT & $\mathrm{CR}$ & $0-3,960$ & $3,784-4,241$ & $\mathrm{C}, \mathrm{S}$ & 0.07 & 12 \\
\hline Leopard cat Prionailurus bengalensis & $\mathrm{LC}$ & VU & $0-3,240\left(4,474^{3}\right)$ & $3,120-4,388$ & $\mathrm{~B}, \mathrm{C}, \mathrm{S}, \mathrm{MT}$ & 0.31 & 102 \\
\hline Chinese mountain cat Felis bieti & VU & $\mathrm{CR}$ & $2,500-5,000$ & $3,838-4,026$ & $\mathrm{C}$ & 0.03 & 8 \\
\hline Pallas's cat Otocolobus manul & NT & EN & $450-5,050$ & $4,787-4,824$ & MT & 0.02 & 3 \\
\hline \multicolumn{8}{|l|}{ Cetartiodactyla } \\
\hline \multicolumn{8}{|l|}{ Suidae } \\
\hline Wild boar Sus scrofa & LC & LC & $0-?$ & $3,105-4,813$ & $\mathrm{~B}, \mathrm{C}, \mathrm{S}, \mathrm{MT}$ & 0.50 & 218 \\
\hline \multicolumn{8}{|l|}{ Moschidae } \\
\hline Forest musk deer Moschus berezovskii & EN & CR & $2,000-3,800$ & $3,345-4,179$ & $B, C, S$ & 0.08 & 84 \\
\hline Alpine musk deer Moschus chrysogaster & EN & $\mathrm{CR}$ & $2,000-5,000$ & $3,471-4,397$ & $\mathrm{C}, \mathrm{S}, \mathrm{MT}$ & 0.09 & 33 \\
\hline \multicolumn{8}{|l|}{ Cervidae } \\
\hline Tufted deer Elaphodus cephalophus & NT & $\mathrm{VU}$ & $300-4,750$ & $3,252-4,375$ & $\mathrm{~B}, \mathrm{C}, \mathrm{S}, \mathrm{MT}$ & 0.36 & 513 \\
\hline Sambar Rusa unicolor & VU & NT & $0-3,900$ & $3,252-4,208$ & $\mathrm{~B}, \mathrm{C}, \mathrm{S}, \mathrm{MT}$ & 0.45 & 715 \\
\hline Wapiti Cervus canadensis & LC & $\mathrm{EN}$ & $0-5,000$ & $4,322-4,600$ & S, MT & 0.05 & 20 \\
\hline
\end{tabular}




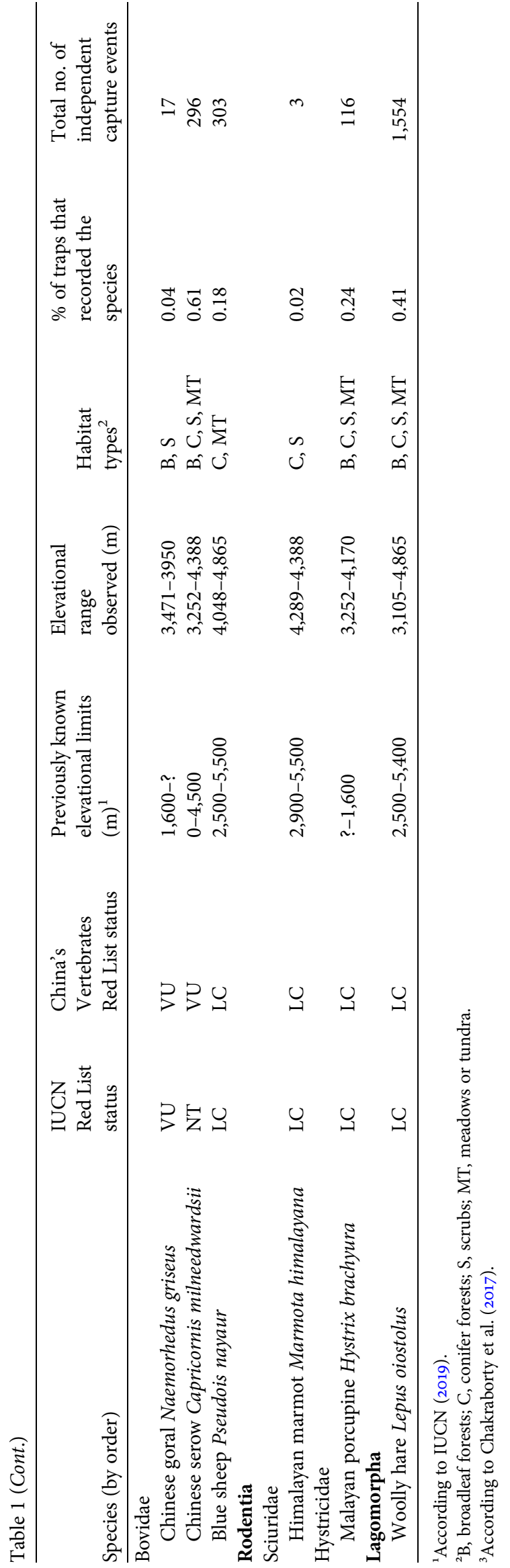

sheep Pseudois nayaur, the wapiti Cervus canadensis, the Himalayan marmot Marmota himalayana and the Altai weasel Mustela altaica) were recorded only in alpine habitat above 4,000 $\mathrm{m}$ (Table 1). We recorded new upper elevation limits for eight species: the Asiatic golden cat Catopuma temminckii $(4,241 \mathrm{~m})$, the grey wolf Canis lupus $(4,843 \mathrm{~m})$, the red fox Vulpes vulpes $(4,865 \mathrm{~m})$, the northern hog badger Arctonyx albogularis $(4,824 \mathrm{~m})$, the sambar Rusa unicolor $(4,208 \mathrm{~m})$, the forest musk deer Moschus berezovskii (4,179 m), the Malayan porcupine Hystrix brachyura $(4,170 \mathrm{~m})$ and the rhesus monkey Macaca mulatta (4,375 m).

The order with the largest number of species recorded was carnivores (16), followed by ungulates (9). Within carnivores, felids were the most diverse, with seven species recorded. The per cent of camera traps that detected a species, and the total number of independent capture events, were highest for two canines, the grey wolf and the red fox, followed by two felids, the leopard Panthera pardus and the leopard cat Prionailurus bengalensis, and one mustelid, the yellow-throated marten Martes flavigula (Table 1). Among the herbivorous species, the per cent of camera traps that detected a species was highest for the Chinese serow Capricornis milneedwardsii, but the woolly hare Lepus oiostolus had the highest number of independent capture events. Other herbivorous species that were detected by a high per cent of camera traps or had a high number of independent capture events were ungulates such as the sambar, the tufted deer Elaphodus cephalophus and the blue sheep (Table 1).

\section{Discussion}

Using camera trapping, we surveyed large and mediumsized mammals in Xionglongxi Provincial Nature Reserve and adjacent areas, on the eastern margin of the Tibetan Plateau. Our record of 29 large and medium-sized mammal species, including 13 globally threatened species and 22 species nationally threatened in China, is higher compared to other areas on the eastern edge of the Tibetan Plateau, highlighting the significant conservation value of this area. We recorded diverse carnivore species; of particular significance was our detection of seven felid species $(58.3 \%$ of the felid species occurring in China). This is the highest documented presence of felid species at the county level in China (Smith \& Xie, 2009) and is high also compared with other areas of the world (Sunquist \& Sunquist, 2017), indicating a globally significant felid community.

Our detection of two cryptic, nocturnal species, the Chinese mountain cat Felis bieti and the Asian badger Meles leucurus, marks the first record of both species on the eastern edge of the Tibetan Plateau. The record of the Chinese mountain cat is particularly important, because it extends the previously known range of this species by c. $400 \mathrm{~km}$ to the south, from the north-eastern edge to the 
eastern edge of the Tibetan Plateau (Fig. 1; Riordan et al., 2015). We recorded the Asiatic golden cat, the grey wolf, the sambar, the forest musk deer and the Malayan porcupine in alpine areas above 4,000 $\mathrm{m}$, where they had not previously been observed (IUCN, 2019). In addition, we detected the northern hog badger, for which the previously recorded upper elevation limit was 4,300 $\mathrm{m}$ (Helgen \& Chan, 2016), in tundra habitat at 4,824 $\mathrm{m}$. The high-elevation records of these species suggest their versatility and adaptability across diverse habitats. Climate change may also push these species to higher elevations.

Leopards commonly live below the tree line (Roberts, 1977; Green, 1987), although they have been recorded at altitudes of up to 5,200 $\mathrm{m}$ in the Himalayas (Stein et al., 2019). In our survey, we obtained independent captures of leopards in rocky, mountainous areas at 4,200-4,400 $\mathrm{m}$, where snow leopards are likely to occur (McCarthy et al., 2017), suggesting that the two leopard species share territory. However, we did not record snow leopards below 4,700 m. Competition may arise when the two leopard species occur sympatrically, because they are approximately the same size and have comparable food requirements (Lovari et al., 2013; Shao et al., 2019). It is possible that, because of climate change, the upper forest limit has shifted to higher altitudes, where both leopard species occur. Consequently, the cold-adapted snow leopards could be confined to more barren, rocky habitats at higher altitudes as the more ecologically flexible leopards expand their territory (Lovari et al., 2013; Buzzard et al., 2017).

We did not record some of the species that, according to the literature (Wang \& Hu, 1999; Peng et al., 2006), occur in the study area, including the Tibetan fox Vulpes ferrilata, the dhole Cuon alpinus, the beech marten Martes foina, the Tibetan gazelle Procapra picticaudata, the argali Ovis ammon and Milne-Edwards' macaque Macaca thibetana. The Tibetan fox and the Tibetan gazelle prefer open grassland habitats. Given that our cameras were deployed in only some isolated patches of meadows or tundra around forests and scrubs (Fig. 1b), we were unable to confirm whether these two species occur in the study area. Local people reported that they had observed beech martens and argalis recently, but had not seen any dholes, or even traces of them, for many years. They also did not mention observing Milne-Edwards' macaque. Further camera trapping that covers a wider elevational range and a variety of microhabitats is needed to ascertain the presence of these species in the area.

The patterns for the per cent of camera traps that detected a species and the total number of independent capture events were similar for most species. When a species occurred at more locations, the capture rate was generally higher. The grey wolf and the leopard were the most dominant large predators. The brown bear Ursus arctos, however, although widespread across much of northern Eurasia (McLellan et al., 2017), was detected relatively rarely, even compared to some threatened species such as the leopard. There are four subspecies of brown bear in China, and the one detected in our study is the Tibetan subspecies Ursus arctos pruinosus, which is endemic to the Tibetan Plateau (Ma et al., 1998). This subspecies was previously estimated to have a small population $(5,000-6,000$ individuals; $\mathrm{Ma}$ et al., 1998), but its current population status is unknown (McLellan et al., 2017). Further studies are needed to examine the distribution and population density of this subspecies at a large scale.

The woolly hare and ungulates such as the sambar, the tufted deer, the Chinese serow and the blue sheep were the main prey species recorded in the study area. The woolly hare was the most dominant and is probably integral to the high-mountain food chains, consuming considerable quantities of plant matter and providing food for large carnivores such as the grey wolf and the leopard (Werhahn et al., 2019). The prey base appears adequate to support large carnivores, but local people reported frequent livestock depredation by large predators such as the grey wolf and the leopard. Given the potential implications of negative human-wildlife interactions (Graham et al., 2005; Xu et al., 2015), we recommend that further studies are conducted in the area, to determine the level of livestock depredation and examine any conflicts.

\section{Conclusion}

Our survey provides important evidence to support conservation efforts in Xionglongxi Provincial Nature Reserve and adjacent areas. Further camera trapping should cover a wider elevational range and a variety of microhabitats, to increase the probability of detecting species that we did not record but that may occur in the area. Given that leopards may have expanded their range into that of snow leopards, we also recommend that interspecific relationships between these two species are examined further. Livestock depredation by leopards should be evaluated, and strategies for compensating herders for losses should be developed, to support the conservation of this species. In addition, we recommend that the protection status of the area should be upgraded. Xionglongxi is currently a provincial nature reserve aiming mainly to protect wetland ecosystems; we propose that a larger and national-level nature reserve should be established in the region of Xionglongxi Provincial Nature Reserve, to protect subalpine and alpine ecosystems, with a focus on felids of conservation concern and with the threatened leopard and snow leopard as flagship species.

Acknowledgements This work was supported logistically and financially by Sichuan Station of Wildlife Survey and Management, Chengdu Leique Eco-environmental Protection Technology Co., Ltd. and Xinlong Forestry Bureau. Additional financial support was provided by the Joint Fund of the National Natural Science Foundation 
of China and the Karst Science Research Center of Guizhou Province (Grant No. U1812401), and the Doctoral Foundation of Guizhou Normal University (Grant No. 2016). We thank Yang Xiang and Li Zhou from Xinlong Forestry Bureau, and Dunwu Qi from Chengdu Research Base of Giant Panda Breeding, for support during fieldwork.

Author contributions Study design: BY, YX, XG; fieldwork: DS, BY; data analysis, writing: YX, BW, DS, BY.

\section{Conflicts of interest None.}

Ethical standards This research was approved by Sichuan Station of Wildlife Survey and Management, and abided by the Oryx guidelines on ethical standards.

\section{References}

Ancrenaz, M., Hearn, A.J., Ross, J., Rahel, S. \& Wilting, A. (2012) Handbook for Wildlife Monitoring Using Camera Traps. BBEC II Secretariat, Sabah, Malaysia.

Anile, S. \& Devillard, S. (2016) Study design and body mass influence RAIs from camera trap studies: evidence from the Felidae. Animal Conservation, 19, 35-45.

Brandt, J.S., Kuemmerle, T., Li, H., Ren, G., Zhu, J. \& Radeloff, V.C. (2012) Using Landsat imagery to map forest change in southwest China in response to the national logging ban and ecotourism development. Remote Sensing of Environment, 121, 358-369.

Bruce, T., Amin, R., Wacher, T., Fankem, O., Ndjassi, C., Ngo BATA, M. et al. (2018) Using camera trap data to characterise terrestrial larger-bodied mammal communities in different management sectors of the Dja Faunal Reserve, Cameroon. African Journal of Ecology, 56, 759-776.

Burton, A.C., Neilson, E., Moreira, D., Ladle, A., Steenweg, R., FISHER, J.T. et al. (2015) Wildlife camera trapping: a review and recommendations for linking surveys to ecological processes. Journal of Applied Ecology, 52, 675-685.

Buzzard, P.J., Li, X. \& Bleisch, W.V. (2017) The status of snow leopards Panthera uncia, and high altitude use by common leopards P. pardus, in north-west Yunnan, China. Oryx, 51, 587-589.

Carbone, C., Christie, S., Conforti, K., Coulson, T., Franklin, N., GinsberG, J.R. et al. (2001) The use of photographic rates to estimate densities of tigers and other cryptic mammals. Animal Conservation, 4, 75-79.

Chakraborty, R., Nahmo, L.T., Upadhyay, J. \& Medhi, K. (2017) High elevation record of the leopard cat in Bhagajang wetland complex, India. CATnews, 66, 22-23.

Chinanews (2018) Leopard was photographed for the first time in the Chaqingsongduo Nature Reserve, Baiyu County, Sichuan. Chinanews. chinanews.com/gn/2018/04-23/8498281.shtml [accessed 5 January 2020].

Dickman, A.J., Hinks, A.E., Macdonald, E.A., Burnham, D. \& Macdonald, D.W. (2015) Priorities for global felid conservation. Conservation Biology, 29, 854-864.

Graham, K., Beckerman, A.P. \& Thirgood, S. (2005) Humanpredator-prey conflicts: ecological correlates, prey losses and patterns of management. Biological Conservation, 122, 159-171.

Green, M.J.B. (1987) The Conservation Status of the Leopard, Goral and Serow in Bangladesh, Bhutan, Northern India and Southern Tibet. IUCN Conservation Monitoring Centre, Cambridge, UK.

Hedwig, D., Kienast, I., Bonnet, M., Curran, B.K., Courage, A., Boesch, C. et al. (2017) A camera trap assessment of the forest mammal community within the transitional savannah-forest mosaic of the Batéké Plateau National Park, Gabon. African Journal of Ecology, 56, 777-790.

Helgen, K. \& Chan, B. (2016) Arctonyx albogularis. In The IUCN Red List of Threatened Species 2016: e.T70206273A70206436. dx.doi.org/ 10.2305/IUCN.UK.2016-1.RLTS.T70206273A70206436.en [accessed 6 January 2020].

Hu, X., Li, J., Luo, X., Zewengtaxu, Chen, X., Zhang, L. et al. (2019) Preliminary survey of mammal and bird biodiversity using camera traps in the Yading National Nature Reserve of Sichuan Province, China. Acta Theriologica Sinica, 39, 333-343.

IUCN (2019) The IUCN Red List of Threatened Species. Version 2019-1. iucnredlist.org [accessed 14 April 2019].

JianG, Z., MA, Y., Wu, Y., WANG, Y., Feng, Z., Zhou, K. et al. (2015) China's mammalian diversity. Biodiversity Science, 23, 351-364.

JiAnG, Z., JiAnG, J., WANG, Y., ZhanG, E., Zhang, Y., LI, L. et al. (2016) Red List of China's vertebrates. Biodiversity Science, 24, 500-551.

JiAnG, Z., LiU, S., Wu, Y., Jiang, X. \& Zhou, K. (2017) China's mammal diversity (2nd edition). Biodiversity Science, 25, 886-895.

LI, S., WanG, D.J., XIAaO, Z.S., LI, X.H., WanG, T.M., FenG, L.M. \& WANG, Y. (2014) Camera-trapping in wildlife research and conservation in China: review and outlook. Biodiversity Science, 22, 685-695.

LI, S., WANG, D.J., Bu, H.L., LIU, X.G. \& Jin, T. (2016) Camera-trapping survey on the mammal diversity of Laohegou Nature Reserve, Sichuan Province. Acta Theriologica Sinica, 36, 282-291.

Lovari, S., Ventimiglia, M. \& Minder, I. (2013) Food habits of two leopard species, competition, climate change and upper treeline: a way to the decrease of an endangered species? Ethology Ecology \& Evolution, 25, 305-318.

MA, Y.Q., XU, L. \& HU, J.C. (1998) On the resources and conservation of bears in China. Life Science Research, 2, 205-211.

McCarthy, T., Mallon, D., Jackson, R., Zahler, P. \& McCarthy, K. (2017) Panthera uncia. In The IUCN Red List of Threatened Species 2017: e.T22732A50664030. dx.doi.org/10.2305/ IUCN.UK.2017-2.RLTS.T22732A50664030.en [accessed 20 January 2020].

McLellan, B.N., Proctor, M.F., Huber, D. \& Michel, S. (2017) Ursus arctos (amended version of 2017 assessment). In The IUCN Red List of Threatened Species 2017: e.T41688A121229971. dx.doi.org/10. 2305/IUCN.UK.2017-3.RLTS.T41688A121229971.en [accessed 27 January 2020].

Mittermeier, R.A., Gil, P., Hoffmann, M., Pilgrim, J., Brooks, T., Mittermeier, C.G. et al. (2004) Hotspots Revisited: Earth's Biologically Richest and Most Endangered Terrestrial Ecoregions. Conservation International, CEMEX, Mexico City, Mexico.

Moo, S.S.B., Froese, G.Z.L. \& Gray, T.N.E. (2017) First structured camera-trap surveys in Karen State, Myanmar, reveal high diversity of globally threatened mammals. Oryx, 52, 537-543.

Myers, N., Mittermeier, R., Mittermeier, C., Da Fonseca, G. \& KeNT, J. (2000) Biodiversity hotspots for conservation priorities. Nature, 403, 853-858.

National Forestry and Grassland Data Center, Sichuan Subcenter (2020) The Forest Inventory Database of Sichuan Province in 2011. sc.forestdata.cn/web/square/industry/1/44 [accessed 10 November 2020].

O’Brien, T.G., Kinnaird, M.F. \& Wibisono, H.T. (2003) Crouching tigers, hidden prey: Sumatran tiger and prey populations in a tropical forest landscape. Animal Conservation, 6, 131-139.

PENG, J.T. \& ZhONG, X.Q. (2005) A Guide to Identification and Conservation of Wild Mammals in Ganzi Tibetan Autonomous Prefecture of Sichuan Province. Sichuan Scientific and Technical Publishers, Chengdu, China. 
Peng, J.T., Zhou, H.M. \& LiU, W. (2006) Investigation on mammal and fauna in Ganzi Prefecture in Hengduan Mountains, southeast of Qinghai-Tibet Plateau. Sichuan Journal of Zoology, $25,747-753$.

PEOPLE.CN (2019) Camera traps reveal the hidden world around us. People.cn. sc.people.com.cn/n2/2019/1218/c345458-33641196.html [accessed 5 January 2020].

Riordan, P., Sanderson, J., Bao, W., Abdukadir, A. \& Shi, K. (2015) Felis bieti. In The IUCN Red List of Threatened Species 2015: e.T8539A50651398. dx.doi.org/10.2305/IUCN.UK.2015-4.RLTS. T8539A50651398.en [accessed 21 June 2019].

Roberts, T.J. (1977) The Mammals of Pakistan. Ernest Benn Ltd., London, UK.

Rovero, F., Martin, E., Rosa, M., Ahumada, J.A. \& Spitale, D. (2014) Estimating species richness and modelling habitat preferences of tropical forest mammals from camera trap data. PLOS ONE, 9, e10330o.

SCOL (2013) The survey of terrestrial wildlife in Garzê and Aba autonomous prefectures has been finished, and some species that have not been seen for many years were rediscovered. SCOL. sichuan.scol.com.cn/fffy/content/2013-12/17/content_6603004.htm? node $=894$ [accessed 3 July 2020].

Sichuan Observer (2017) More than ten rare wildlife were photographed by camera traps in Yajiang County, Sichuan. Sichuan Observer. cbgc.scol.com.cn/news/20807 [accessed 5 January 2020].

Shao, X., Song, D., Huang, Q., Li, S. \& Yao, M. (2019) Species identification and molecular diet analysis of carnivores based on fecal DNA and metabarcoding. Biodiversity Science, $27,543-556$.

SHEN, X. (2008) The role of Tibetan traditional cultures in biodiversity conservation in western China. PhD Dissertation, Peking University, Beijing, China.

Shi, B.N. \& Zhно, E.M. (1982) Fauna of Sichuan (Overview). Sichuan People's Publishing House, Chengdu, China.

Smith, A.T. \& Xie, Y. (2009) A Guide to the Mammals of China. Hunan Educational Publishing House, Changsha, China.
Sollmann, R., Mohamed, A., Samejima, H. \& Wilting, A. (2013) Risky business or simple solution - Relative abundance indices from camera-trapping. Biological Conservation, 159, 405-412.

State Forestry Administration (2009) National Survey of Key Terrestrial Wildlife Resources in China. China Forestry Publishing House, Beijing, China.

Stein, A.B., Athreya, V., Gerngross, P., Balme, G., Henschel, P., Karanth, U. et al. (2019) Panthera pardus (amended version of 2016 assessment). In The IUCN Red List of Threatened Species 2019: e.T15954A160698029. dx.doi.org/10.2305/IUCN.UK.2016-1.RLTS. T15954A160698029.en [accessed 20 January 2020].

Sunquist, M. \& Sunquist, F. (2017) Wild Cats of the World. University of Chicago Press, Chicago, USA.

Wang, Y.Z. \& Hu, J.C. (1999) The Colour Pictorial Handbook of Mammals in Sichuan. China Forestry Publishing House, Beijing, China.

Werhahn, G., Kusi, N., Li, X., Chen, C., Zhi, L., Lázaro Martín, R. et al. (2019) Himalayan wolf foraging ecology and the importance of wild prey. Global Ecology and Conservation, 20, eoo780.

WU, Y., YU, Z.W. \& PenG, J.T. (1989) Note on survey of wildlife resources in Garzê Tibetan Autonomous Prefecture, Sichuan Province. Sichuan Journal of Zoology, 8, 8.

XiaO, Z.S., Li, X.Y., Xiang, Z.F., Li, M., Jiang, X.L. \& Zhang, L.B. (2017) Overview of the mammal diversity observation network of Sino BON. Biodiversity Science, 25, 237-245.

Xinhua (2018) The construction of ecological civilization in the Tibetan Plateau. Xinhua. xinhuanet.com/2018-07/18/c_1123141752. htm [accessed 19 January 2020].

Xu, Y., YANG, B. \& Dou, L. (2015) Local villagers' perceptions of wolves in Jiuzhaigou County, western China. PeerJ, 3, e982.

Zhang, B.P., ChenG, X.D., LI, B.L. \& YAO, Y.H. (2002) Biodiversity and conservation in the Tibetan Plateau. Journal of Geographical Sciences, 12, 135-143.

Zнао, F. \& Lu, T. (2017) Ecological effects of roads on land use and landscape pattern in Eastern Tibetan Plateau, China. Ecological Science, 36, 146-151.

Zhu, S.Q. \& Xiang, Y. (2015) Xionglongxi Nature Reserve. Green Tianfu, 7, 34-35. 